\title{
PROPUESTA PRELIMINAR PARA EL ANÁLISIS \\ De la Disertación JuRídica de Mariano Moreno (CharCas, 1802)
}

\author{
Preliminary proposal for the analysis of the Disertación juridica \\ of Mariano Moreno (Charcas, 1802)
}

\author{
Carlos María Chiappe*
}

\section{RESUMEN}

El objetivo de este artículo es realizar un análisis preliminar de una fuente documental, cuyo autor es el rioplatense Mariano Moreno, que se titula Disertacion juridica. Sobre el servicio personal delos Indios en general, y sobre el particular de Yanaconas y Mitarios. Que se ha de leer en la R.l Academia de práctica de Jurisprudencia de esta Ciudad, por el Academico que suscribe, el día [falta] de Agosto de 1802. El valor de este trabajo radica, en primer lugar, en la descripción analítica del contenido de la fuente, efectuada reponiendo los "vacíos" derivados de su abundante contenido indexical; en segundo lugar, en el acercamiento a su contexto de producción. En las conclusiones se propone un planteamiento desde el marco teórico de la antropología histórica, entendiendo que este es funcional para explorar los múltiples estratos de significación que la fuente contiene.

Palabras Clave: Mariano Moreno, disertación jurídica, Cuestión indígena, Siglo XiX temPRANO, ELITES CRIOLLAS.

\footnotetext{
* Universidad de Buenos Aires, Facultad de Filosofía y Letras. Instituto de Ciencias Antropológicas (ICA), Buenos Aires, Argentina. Correo electrónico: carlosmariachiappe@gmail.com.
} 


\section{Abstract}

The aim of this article is to make a preliminary analysis of a documentary source whose author is the rioplatense Mariano Moreno, and which is entitled Disertacion juridica. Sobre el servicio personal delos Indios en general, y sobre el particular de Yanaconas y Mitarios. Que se ha de leer en la R.l Academia de práctica de Jurisprudencia de esta Ciudad, por el Academico que suscribe, el dia [lack] de Agosto de 1802. The value of this work lies in the first place, in which an analytical description of the content of the source, replacing the "empty" derived from its abundant content attenuated indexical trace. In the second place, which is an approach to its context of production in order to achieve a more comprehensive knowledge of the same. In the conclusions it is proposed an approach from the theoretical framework of historical anthropology, with the understanding that the same is functional to explore the multiple layers of significance that the source contains.

Keywords: Mariano Moreno, legal dissertation, indigenous matter, early XiX Century, CREOLE ELITE.

Recibido: 27 de julio de 2016.

Dictamen 1: 7 de febrero de 2017.

Dictamen 2: 3 de abril de 2017. 


\section{Agradecimientos}

Estoy en deuda con la Dra. Lorena Rodríguez, que realizó una primera lectura de la nota, y con los evaluadores, por sus inestimables apreciaciones que me permitieron mejorar el trabajo.

\section{INTRODUCCIÓN}

El objetivo de esta nota es proponer algunas líneas de análisis sobre la fuente Disertacion juridica. Sobre el servicio personal delos Indios en general, y sobre el particular de Yanaconas y Mitarios. Que se ha de leer en la R. I Academia de práctica de Jurisprudencia de esta Ciudad, por el Academico que suscribe, el dia [falta] de Agosto de 1802 (en adelante la Disertación). ${ }^{1}$ La categoría de servicio personal hace referencia genérica a las contribuciones de los pueblos originarios en beneficio de la Corona española (v.g. mita minera) o de particulares (v.g. trabajo de servidumbre, lo que en la actualidad se entiende, stricto sensu, por servicios personales).

La Disertación - primera obra conocida de Mariano Moreno- fue presentada en la Academia Carolina de Charcas como uno de los requisitos para obtener el título de abogado. Siguiendo a De Gori (2016, p. 201), sostengo que a través del análisis de este tipo de fuentes documentales "es posible presentar cómo los letrados y hombres de saber se apropiaron, articularon y resignificaron imaginarios y concepciones políticas sobre el orden político para fundamentar sus propuestas y las de las élites políticas a las que pertenecían o las que comenzaban a afirmarse en el escenario político". En el caso particular de la Disertación, un adecuado análisis puede alu mbrar — a partir de su tema primario, la cuestión indígena-indicios de la ideología e intereses del grupo de pertenencia del autor: la élite criolla de Buenos Aires, en particular, y de Sudamérica, en general.

Mi intención es avanzar en la propuesta desde la perspectiva de la antropología histórica, marco teórico que permite combinar el análisis de la estructura social con el de los acontecimientos y los enfoques en escalas micro y macro. Sabido es

1 En general, se entiende por disertación una presentación realizada con el fin de "razonar, discurrir detenida y metódicamente, sobre alguna materia, bien para exponerla, bien para refutar opiniones ajenas” (RAE, 2016). En el caso de las antiguas disertaciones (tal la Disertación de Mariano Moreno), estas tenían un valor similar a las actuales tesis universitarias y sus respectivas defensas, con su estructura común de entrada, exposición, desarrollo, aspectos centrales y conclusiones. 
que, en términos generales, desde hace ya varias décadas los límites disciplinares se ha vuelto lábiles, lo que propició el surgimiento de espacios trans o multi disciplinares. En el caso específico de la antropología y de la historia, a partir de la década de 1960 se reestableció el diálogo entre estas disciplinas y, posteriormente, se ensayaron diversas formas de articulación. La antropología histórica es producto de estos cambios, y su especificidad radica en atender de modo simultáneo las lógicas nativas y la profundidad temporal para abordar el estudio y la compresión de los procesos sociales. Se parte de la idea de que existen diversas formas colectivas de interpretar y accionar en el mundo, y que estas lógicas no son inmutables, sino que se transforman a lo largo del tiempo, en un interjuego entre capacidad de acción y condicionamientos que la limitan. La propuesta de la antropología histórica es que, para comprender en profundidad las problemáticas de nuestro tiempo, es imprescindible analizarlas atendiendo la profundidad de su conformación histórica y poniendo en tensión nuestras propias categorías de análisis con aquellas que surgen de la investigación (Sahlins, 1985; Lorandi y Wilde, 2000; Ramos 2016). En este marco, las cuestiones tratadas por Moreno en la Disertación pueden servir para alumbrar determinadas genéticas de la cuestión indígena, las cuales siguen siendo centrales en el contexto actual, ya que los viejos conflictos siguen vigentes, como lo es en el caso paradigmático del territorio y sus recursos.

Considero que la Disertación aún no ha sido explorada desde la perspectiva de la antropología histórica, aunque esta fuente y — más en general — las ideas y actividades políticas de Moreno han sido revisadas desde hace tiempo por los historiadores. Aquí sería gravoso reseñar el gran número de obras atinentes; valga como ejemplos extremos - en lo temporal y en el tipo de enfoque- los trabajos tempranos de Ricardo Levene $(1921,1948)$ ligados a la construcción de la historia nacional de Argentina, centrada en los "grandes hombres" o "próceres", y la contemporánea de Esteban de Gori (2012), en la que se busca "dar cuenta de las relecturas, apropiaciones y resemantizaciones que las élites insurgentes realizaron sobre las culturas políticas hispánicas en el marco de los procesos revolucionarios e independentistas en el Río de la Plata" (Wieczorek, 2012, p. 240) valiéndose de aportes de la hermenéutica, la sociología política y la historia conceptual (Manzanelli, 2014, p. 1).

El texto de la Disertación fue extraído del libro Escritos, compilación realizada por Levene (1943) de toda la documentación obra de Mariano Moreno existente en el Archivo General de la Nación (Buenos Aires, Argentina). La extensión de la fuente publicada es de 28 páginas en letra de molde, y conserva la ortografía y gramática original, las que utilizo sin cambiarlas en tanto las diferencias con los 
usos contemporáneos no constituyen impedimento para la comprensión del texto.

$\mathrm{Al}$ parecer el documento se encontraba, a la fecha de ser transcripto, en buen estado de conservación, ya que son pocas los faltantes indicados. La fuente está constituida por una introducción, una parte primera ("Del servicio de los indios en general") y una segunda ("Del servicio de los indios en particular"). De esta existe una edición anterior en la Revista de Derecho, Historia y Letras (Moreno, [1802] 1911). Por otra parte, algo realmente notorio de la forma de escritura es el abundante repertorio de carácter indexical. El estilo del autor obliga a un trabajo de reposición, necesario para una comprensión más acabada del texto, y de ahí las abundantes notas al pie o aclaraciones entre corchetes.

En cuanto a la presentación formal, la presente nota consta de dos apartados. En el primero, trato su contexto de producción, coincidente con el clima convulsionado del periodo comprendido entre las reformas borbónicas y el comienzo de las revoluciones independentistas. En el segundo, realizo una descripción analítica del contenido de la fuente, tanto de su introducción como de sus partes primera y segunda. En las conclusiones, en cuanto el presente texto tiene características de nota y no de artículo que da cuenta de una investigación concluida, adelanto posibles líneas de pesquisa que serán profundizadas en el futuro.

\section{EL CONTEXTO DE PRODUCCIÓN DE LA FUENTE}

Mariano Moreno (1778-1811) fue un abogado, periodista y político nacido en Buenos Aires y uno de los impulsores de la Revolución de Mayo (1810), antecedente de la independencia de las Provincias Unidas del Río de la Plata (1816), hoy República Argentina. En 1800, Moreno llegó a Charcas (Chuquisaca, actual Bolivia) para realizar estudios superiores en teología. Si bien no pertenecía a una familia de altos recursos, sus relaciones familiares le permitieron alojarse y ser mantenido por un miembro de la aristocracia altoperuana, el canónigo Terrazas (Tabarrozzi, 2012).

Desde hacía algunos años habían estado produciéndose en la América española cambios profundos relacionados con las reformas burocráticas introducidas por la Casa de Borbón, como el aumento del control y de la recaudación fiscal y la reorganización territorial en unidades políticas más reducidas. Como consecuencia, el territorio altoperuano al que Moreno llegó dependía entonces del Virreinato del Río de la Plata, creado en 1776. Las reformas, en suma, propiciaron profundos 
reacomodos de las relaciones sociales que habían venido constituyéndose desde los tiempos iniciales de la Conquista, aunque sin mejorar la situación de los criollos, para quienes seguían vedados los cargos públicos, manteniéndose también la inveterada sujeción de los pueblos originarios. A causa de este panorama, el fin del siglo XVIII constituyó una coyuntura explosiva protagonizada por un ciclo de rebeliones, de las cuales las de Tupac Amaru y Tupac Katari (1780-1783) fueron su punto más alto (O’Phelan, 1988; Serulnikov, 2010; Walker, 1990; Flores Galindo, 1993).

Señala de Gori (2016, p. 200) que el periodo de crisis que va desde mediados del siglo XVIII hasta principios del XIX llevó a los "hombres de saber" a buscar en "los imaginarios y lenguajes políticos" del universo simbólico de la Corona española, "aquellas concepciones y vocabularios que entendieron como eficaces para lograr la adhesión y lealtad a un orden, ya sea para reformarlo, conservarlo o trastocarlo". Estas coyunturas críticas "se presentaron como momentos oportunos para la escritura, como para una intervención que buscó efectos performativos en el terreno político e imaginario".

La ciudad de Charcas era por entonces el centro administrativo del cual dependía Potosí (actual Bolivia), el mayor centro minero de América del Sur, y sede del Arzobispado, de la Real Audiencia y de la Universidad de San Xavier (Tabarrozzi, 2012). Por su ubicación, función e instituciones, esta constituyó un "centro regional de alta incidencia en la cuestión indígena y especialmente en la formación intelectual e ideológica de un importante sector de la elite revolucionaria de Mayo" (Seghesso, 2010, p. 2).

Con el apoyo del canónigo Terrazas, Moreno terminó sus estudios en Teología en 1801 y se abocó al Derecho. Al mismo tiempo, se incorporó, a través de lecturas y reuniones, a la vida intelectual de la ciudad. Se reconoce que las influencias más notorias que recibió por aquella época fueron la de los revolucionarios franceses (Moreno fue el traductor del Contrato social, de Rousseau), la del despotismo ilustrado español, "especie de ilustración, que no debía atentar contra la monarquía ni contra el dogma católico ni contra la interpretación escolástica de las escrituras" (Tabarrozzi, 2012) y la de la Constitución de los Estados Unidos, texto que también tradujo.

Por otra parte, los estudios en la Universidad lo pusieron en contacto con Victorián Villava, Fiscal y Protector de Naturales en la Real Audiencia de Charcas. Moreno participó en la Academia Carolina de práctica forense, institución creada en 1780. Sobre los cursos que se dictaban, dice Tabarrozzi $(2012$, p. 6) que "eran sobre derecho general y derecho indiano [lo que] muestra que, desde la mitad del siglo 
XVIII en adelante, a medida que las ideas ilustradas [...] llegaban al elemento culto de la población del virreinato [estas impulsaron] los estudios de derecho patrio".

Pocos años antes de la Disertación, y contextualizada en el ciclo de declinación del cerro Potosí, lo que aumentaba la dureza de las labores y el riesgo de vida de los mineros, se había dado una discusión pública alrededor del trabajo mitayo entre dos actores de intereses opuestos. Por un lado, en 1793, desde la ciudad de Charcas y en defensa de los intereses indígenas, Villava (quien sería maestro de Moreno), en su calidad de Fiscal y Protector de Naturales, escribió su Discurso sobre la mita de Potosíal Consejo de Indias. Con él se alinearon los indios mitayos y el benefactor de Moreno, Terrazas (Seghesso, 2010). Del otro lado, representando los intereses de los mineros y azogueros, el intendente de Potosí, Francisco de Paula Sanz (asesorado por el jurista Pedro Vicente Cañete, ambos coalicionados con el Protector de Naturales de la ciudad, J. J. Rúa) le respondió al año siguiente en su Contestación (Tabarrozzi, 2012). Estas discusiones se daban al mismo tiempo que Paula Sanz ampliaba las concesiones para la explotación minera del cerro, situación relatada en la Disertación:

Sin embargo, todo esto de la nueva Mita concedida a Dn Luis de Orueta Azoguero de Potosí, las dificultades, que se encontraron, para verificarlay la oposición, que padeció de algunos Magistrados [de la Real Audiencia de Charcas] su plantificación, formaron un excesivo incendio [...] Encendidos los ánimos con el fuego de la disputa, jamas se ha ventilado con mayor ardor la cuestión de la legitimidad de la mita. El Sor Dn Victorian de Villaba Fiscal qe fue de esta Rl Audiencia, se esmeró en impugnarla en diversas representaciones y recursos [agregando irónicamente que] El Sor Dn Vicente Cañete Asesor de la Intendencia de Potosí y Oidor honorario de esta Rl Audiencia se opuso [...] con otros doctos escritos, que conservan con aprecios los Literatos de buen gusto (Moreno, [1802] 1943, pp. 28-29).

Un año después (1795), Villava cerró el debate con su Contraréplica. El centro de la discusión radicaba en dirimir si la explotación minera de Potosí era un negocio particular (la postura de Villava) o de la Corona (la de Sanz). Villava entendía que los monarcas no habían querido apropiarse de las minas, sino dejarlas para que se beneficiase de ellas el primer descubridor (a cambio del debido tributo). Por ello, debían reputarse como propiedades y posesiones particulares y, en consecuencia, podían utilizarse para su explotación solo indios voluntarios. Por otro lado, Sanz se hacía fuerte en que sobre el tema minero seguían vigentes las Ordenanzas del virrey Toledo (1574) que afirmaban la propiedad del rey sobre todos los minerales 
americanos y, paralelamente, disponía su concesión a los vasallos que los descubrieren para que sean aprovechados (Seghesso, 2010). Como puede verse, entender la naturaleza pública o privada de las minas era un tema central para saber si los indios podían ser obligados o no a trabajar en ellas.

Lo interesante de la labor del maestro de Moreno es que de su discurso emerge un "concepto antropológico sobre el indígena y una revisión jurídico-crítica de la cuestión laboral minera” (Seghesso, 2010, p. 31). En efecto, Villava caracteriza como un prejuicio la - para algunos - natural indolencia del indio, puntualizando que en la constitución humana participaban factores modeladores del carácter como el clima, la educación y la constitución del gobierno. Además, si bien reconocía el derecho de regalía de la Corona, negaba que la minería fuera trabajo público, ya que esta respondía claramente a intereses privados. Por lo tanto, no se podía forzar a los indios a trabajar en ella. De este modo, "alejándose de la condena social que pesaba sobre la vagancia, argumentaba en favor de una especie de ocio justificado al aseverar [que] no se podía obligar al indio a trabajar para tener lo que no le apetecía" (Seghesso, 2010, p. 32).

Tomando como referencia la anterior discusión, es evidente que la Disertación es una continuidad del debate, pero enmarcada en un mayor deterioro del poder de la Corona, visible en las insurgencias de las diversas castas, en las renovadas apetencias de las potencias extranjeras sobre los territorios españoles (peninsulares y americanos) y en los inminentes procesos independentistas. En definitiva, tanto Villava, antes, como Moreno, después, dieron cuenta de las contradicciones generadas por las reformas borbónicas y propusieron otras formas para lograr su superación (De Gori, 2016, p. 210).

\section{LA DISERTACIÓN}

\section{Introducción}

En 1802 Moreno presentó su Disertación, documento que retomó el tema desarrollado por Victorián de Villaba en su Discurso sobre la Mita (1793), el cual se había enmarcado en una disputa jurídica sobre la situación de los indígenas y el orden político (De Gori, 2016, p. 208). Este tema estaba contextuado, a su vez, en las tensiones finiseculares relacionadas con las reformas borbónicas (tales como la rebelión de amarus y cataris), por lo que tenía gran actualidad. 
El primer tópico que trae a colación Moreno es la antigua discusión sobre la naturaleza humana de los indígenas americanos (Moreno, [1802] 1943, p. 5). La conquista de América inició un ciclo de explotación de sus riquezas naturales en el que los indígenas fueron perseguidos solo por su condición de originarios. El autor realiza una exégesis de los indígenas retratándolos como buenos salvajes rousseaunianos: "Quando su policia ${ }^{2}$ y natural cultura eran dignas de la admiración del Mundo antiguo ${ }^{3}$ no trepidó la maledicencia dudar publicamente en la Capital del Orbe christiano [Roma] acerca de su racionalidad ${ }^{4}$ y para arruinar un delirio, que parecía no necesitar mas anathemas, que los de la humanidad, fue necesario que fulminase sus rayos el Vaticano"s (Moreno, [1802] 1943, p. 6).

El segundo tema es la sumisión a la esclavitud de los indígenas por parte de los conquistadores, "impelidos por barbaros exemplos de la antigüedad [...] seducidos por los ciegos impulsos de su propia pasion”. Aquí introduce las posiciones de dos religiosos opuestos en sus perspectivas: el "Obispo de Darien Dn Sr. Thomas Ortíz", ${ }^{6}$ quien afirmaba que los "habitantes de las Indias eran a natura siervos [...] fundado sin duda en una extravagante doctrina de Aristóteles", ${ }^{7}$ y el "Obispo de Chiapa" , con la postura contraria, y un tercer actor que se erige como árbitro: el "Sor Emperador Carlos 5" y sus consejos (Moreno, [1802] 1943, p. 6).

A partir de aquí, Moreno pasa a caracterizar históricamente la postura de los reyes de España en relación con este debate. Dice que estos siempre habían defendido la libertad "legítima y perfecta" de los indígenas eximiéndolos de los servicios que solo podrían ser exigidos a esclavos. Pero "los efectos no han correspondido a tan amorosas Providencias [...] en tiempos posteriores se han visto sogetos a algunos servicios [...] que no son compatibles con su privilegiada libertad" (Moreno, [1802] 1943, p. 7).

\footnotetext{
2 Por "cortesía, buena crianza y urbanidad en el trato y costumbres", término actualmente en desuso (RAE, 2016).

3 Aquí el autor puede estar refiriéndose a las ideas sobre el particular de filósofos como Jean Jacques Rousseau y el Barón de Montesquieu.

4 Indica la discusión sobre la naturaleza del hombre americano, en la cual intervino el papa con la Bula Subliminis Deus (1537), la cual señaló que los indígenas eran hombres libres, capaces de gobernarse a sí mismos y de recibir la fe cristiana (Hanke, 1982).

5 El sentido total de la frase estaría indicando que la humanidad de los americanos se podría haber probado apelando solo a la razón, lo que evidencia la influencia de las ideas iluministas en el autor.

6 Se refiere a fray Tomás Ortiz, quien en 1526 encabezó la primera misión dominica hacia la Nueva España.

7 Se trata de la doctrina de siervos a natura de Aristóteles, presente en La Política, en donde el filósofo justifica la esclavitud como un hecho natural de la sociedad humana (Arrom, 1992: 77-78).

8 Se refiere a fray Bartolomé de Las Casas.

9 Rey de España con el nombre de Carlos I (1515-1556) y emperador como Carlos V (1520-1558).
} 
Moreno adelanta así el nudo de su argumentación: la contradicción entre una jurisprudencia real que amparaba a los indígenas y una praxis nacida de las características del proceso de conquista en donde los indígenas fueron utilizados como mano de obra esclava. En referencia a esto, el autor dice que por medio de la Disertación "intenta cumplir [...] con el interes qe uno debe mirar los derechos de aquellos hombres, cuyas regiones habita” (Moreno, [1802] 1943, p. 7).

\section{"Del servicio de los indios en general"}

Moreno enumera aquí los argumentos que deberían impedir la esclavitud de los indígenas. Los hay de tres tipos: argumento propter timorem o jurisprudencia que se remonta a los tiempos iniciales de la Conquista. Los Reyes Católicos querían "qe los Indios sean libres en igual modo a los antiguos vasallos de la Corona de Castilla [lo que quedó asentado en la] Cedula [del año] 1542"10 (Moreno, [1802] 1943, p. 8) prohibiendo los servicios personales de los indígenas. Sobre este punto, es curioso que Moreno no se retrotrajera a disposiciones monárquicas anteriores en los que los Reyes Católicos declaraban a los indígenas libres y no sujetos a servidumbre. ${ }^{11}$ A este respecto, las Leyes Nuevas (1542, reinado de Carlos I) fueron la resultante de un proceso mediado por las leyes de Burgos (1512, reinado de Fernando II), en el que los indígenas fueron perdiendo protección real.

Argumento propter conscientiam, con el cual Moreno introduce a otro actor religioso: "el Sor Dn Fr. Juan Garcés del Orden, obispo del Tlaxclala", ${ }^{12}$ que en 1536 dirigió una carta al papa "Sor Paulo tercero [para] demostrar el [...] engaño [de los que] enseñaban qe los Indios debian vivir sugetos [a la esclavitud]”. Según Moreno, esta carta fue el fundamento para que en $1537^{13}$ el sumo pontífice declarara que los indígenas eran capaces de ser evangelizados y que esto debía hacerse "por buenos y blandos medios" so pena de excomunión (Moreno, [1802] 1943, p. 9).

Argumento filosófico (socrático): "siendo la libertad [...] una facultad de hacer de sí un hombre lo que quisiese sin coartación alguna [...] toda precisión a un servicio

10 Las Leyes Nuevas de 1542 preveían la supresión del sistema de encomiendas, (por el cual un grupo de indios era asignado a un encomendero, quien se beneficiaba con su trabajo y a cambio le otorgaba "protección" y se obligaba a evangelizarlo), una vez que vacaren las existentes, prohibían los servicios personales y obligaban a tasar el tributo (para que fuese acorde con las posibilidades de la fuerza de trabajo indígena) (Lorandi, 2002).

${ }^{11}$ Los Reyes Católicos fueron Fernando II de Aragón e Isabel I de Castilla, soberanos de la Corona de Castilla (1474-1504) y de la Corona de Aragón (1479-1516). En realidad, solo Fernando participó de las Leyes de Burgos ya que Isabel había fallecido en 1504 .

12 El dominico Fray Julián Garcés arribó a Nueva España en 1526 y escogió a Tlaxcala como su nueva sede episcopal.

13 Hace relación nuevamente a la Bula Subliminis Deus. 
[es] incompatible con esta natural indiferencia”. Es decir, argumento basado en un silogismo truncado: "los hombres nacen libres, los indígenas son hombres, ergo los indígenas son libres.

Posteriormente, el autor vuelve al inicio de la conquista. Por entonces, la sumisión a la esclavitud estaba prohibida por los Reyes Católicos pero los conquistadores alegaban necesitar el trabajo indígena para "servicios de sus Casas, beneficios de las Minas, cría y guarda de los ganados, labor de los campos y otros diversos Ministerios". Esta solicitud era ilegítima, pero fue tenida por buena por Cristóbal Colón, y de allí se originaron los repartimientos de indios. ${ }^{14}$ Esto fue continuado por Nicolás Ovando ${ }^{15}$ y seguido por Fernando Cortés ${ }^{16}$ en la Nueva España y Franco Montejo ${ }^{17}$ en la Provincia de Yucatán. Es decir que el fenómeno de la esclavitud pasó, con la expansión de la Conquista, del Caribe a Centroamérica.

Un nuevo hito que remarca Moreno en la supresión de la libertad indígena fue la derrota de Diego de Almagro "el Mozo" por el "Licenciado Christoval Baca de Castro" 18 en 1542, quien repartió indios a los leales a la Corona, aunque aclara que la ejecución de este repartimiento se dejó en suspenso para evitar problemas con los que lucharon del lado de la Corona pero no fueron beneficiados ${ }^{19}$ (Moreno, [1802] 1943 , p. 10). Posteriormente, en 1548 , el licenciado Pedro de la Gasca ${ }^{20}$ premió a los leales a la Corona con el repartimiento de 150 encomiendas $^{21}$ (Moreno, [1802] 1943, p. 11). Lo que no queda bien aclarado en la Disertación es que las guerras civiles del Perú fueron fundamentalmente una contienda entre los encomenderos y la Corona española, en la que los primeros intentaron mantener sus privilegios (servicios personales y perpetuidad de las encomiendas), y la segunda intentaba

14 Se refiere aquí al origen de las primeras encomiendas, no de los repartimientos, que iniciaron a mitad del siglo XVI (Elliot, 1990).

15 Gobernador de La Hispaniola (Haitíy República Dominicana) en 1501, propulsor del sistema de mano de obra forzosa o encomienda. Primitivamente utilizado para el trabajo en minas y campos, no incluía el reparto de tierras o de rentas, estando los indígenas asalariados (Elliot, 1990).

16 Hernán Cortés Monroy Pizarro Altamirano (1485-1547), conquistador español del imperio azateca, I marqués del Valle de Oaxaca, gobernador y capitán general de la Nueva España.

17 Nombrado "Adelantado, Capitán General y Alguacil Mayor de Yucatán, Cozumely Tabasco" en 1526 por Carlos I de España.

18 El autor se estárefiriendo al periodo de guerra civil durante la conquista del Perú. En 1542, el gobernador Cristóbal Vaca de Castro derrotó a Diego de Almagro el Mozo en la batalla de Chupas (Lorandi, 2002).

19 Se trata del alzamiento de Gonzalo Pizarro, que llevó a que se suprimiera el capítulo de las leyes Nuevas en el cual se prohibía la encomienda hereditaria (Lorandi, 2002).

20 Esto es luego de la derrota de Gonzalo Pizarro en la batalla de Jaquijahuana en 1548 (Lorandi, 2002).

${ }^{21}$ Lo que se conoce como el reparto de Guaynarima (Lorandi, 2002). 
consolidar el poder real sobre los nuevos territorios conquistados, manteniendo a raya - y a la vez utilizando - la presencia de los encomenderos.

En resumen, hasta aquí la historia narrada por Moreno le sirve para argumentar que, desde el inicio de la conquista, las disposiciones reales declaraban a los indios libres y no sujetos a servidumbre, pero que esta amplia cobertura se fue recortando en la dinámica histórica. En 1512, los Reyes Católicos promulgaron las Leyes de Burgos, que compatibilizaron la encomienda con el principio de libertad de los indios y establecieron los derechos y obligaciones de los encomenderos. Más tarde, la Leyes Nuevas (1542, reinado de Carlos I), que lograron ser aplicadas aplacando los continuos alzamientos de los encomenderos, establecieron la no perpetuidad de las encomiendas, la prohibición de que los indios prestasen servicios personales y la tasación del tributo (Elliot, 1990; Arrom, 1992). Moreno resalta que el espíritu de la ley indiana fue siempre que el tributo al rey no se pagase con servicios personales de los indígenas hacia los conquistadores. Por lo tanto, en la parte primera, el autor busca demostrar la contradicción entre las leyes reales que otorgaban al indio el mismo estatuto que a cualquier otro vasallo de la Corona y las prácticas de los conquistadores. Así, contra la voluntad real, los indígenas fueron forzados a realizar servicios personales no compatibles con su condición de vasallos.

En resumen, Moreno arma su argumentación con base en un recorrido histórico en el que presenta la jurisprudencia atinente y los sucesos que llevaron a desvirtuar el espíritu de las disposiciones reales. Además, presenta tres tipos de argumentos contra el servicio personal: uno de orden legal, otro de orden moral y uno último de orden filosófico. El tercero marida con su ideología liberal, ya que expresa que la mera razón podría ser invocada para defender el estatuto del indígena como hombre libre. Libre en el sentido que esto puede tener bajo un régimen monárquico, en donde se daba la mutua obligación del pacto de vasallaje. Es en este sentido en el que invito a leer la afirmación presente en la introducción de que la racionalidad del hombre americano podría ser defendida por la humanidad obviando la intervención papal. En la misma parte de la obra, Moreno dice que "intenta cumplir [...] con el interés qe uno debe mirar los derechos de aquellos hombres, cuyas regiones habita" (Moreno, [1802] 1943, p. 5). Esta frase es también interesante porque el autor se sitúa a sí mismo como habitante de un lugar con pobladores preexistentes que, en virtud de esta autoctonía, poseen derechos que deben ser defendidos. Al remarcar la existencia de una comunidad de intereses entre los americanos (criollos e indígenas), la continua invocación a la bondad real parece operar como un paraguas 
bajo cuya protección el autor dispara contra los abusos de la casta peninsular que detenta el poder desde los años iniciales de la conquista.

\section{"Del servicio de los indios en particular"}

En la parte segunda, Moreno analiza en detalle dos instituciones: la mita y el yanaconazgo. Si bien ambas tienen su génesis antes de la conquista, se debe recordar que las trata en el sentido que habían adquirido bajo el régimen colonial. El autor comienza diciendo que el origen de los corregidores ${ }^{22}$ se debió, por un lado, a "los delitos de los Indios espiaclmte de los Caciques no menos qe los abusos de los Encomenderos y excesos de los Curas doctrineros [...] Las extorsiones y la novedades executadas ${ }^{23}$ provocaron la huída ${ }^{24}$ de muchos habitantes indígenas que tenían por menos mal vivir errantes, qe sugetarse á las opresiones y servicios de sus Amos, Jueces y Curas". Moreno comenta que el "Emo Sor Dn Francisco de Toledo ${ }^{25}$ quiso subsanar el impedimiento que para la evangelización significaban las grandes distancias entre los puevlos, unificándolos en varios pueblos grandes [pero lo que siguió de esto fue que] las diversas Naciones que congregó [...] tenían diferentes lenguas y costumbres [y] en breve tiempo perdieron la concordia" (Moreno, [1802] 1943, p. 17).

Estas enemistades, según Moreno, terminaron por acabar con los pueblos de indios. Los indios fugados, o bien se refugiaron en chacras y haciendas de los españoles, o bien continuaron errantes sin asentarse en un punto fijo, o bien se radicaron en ciudades. ${ }^{26}$ "Los primeros son los que se llaman Yanaconas de Chacras, los segundos y terceros Yanaconas de la Rl Corona [...] En tiempo de la visita del virrey Francisco de Toledo $^{27}$ gran cantidad de yanaconas radicados en las ciudades

22 Los corregimientos fueron entidades administrativas creadas en la segunda mitad del siglo XVI. Estaban gobernados por un corregidor con funciones administrativas, policiales y judiciales.

23 En este caso se hace alusión a las reformas toledanas, que concentraron a la población indígena en "pueblos de indios", regularon tasa y tributo, establecieron el sistema forzado de mita minera y apuntaron en general a un aumento del poder de la Corona en detrimento del de los encomenderos (Andrien, 1996).

24 Se hace referencia al fracaso de la política toledana (el despoblamiento de los "pueblos de indios") y al hecho de que finalmente los sucesores de Pizarro en la élite colonial triunfaron sobre el poder estatal mediante la corrupción, la ineficiencia y la cooptación (Andrien, 1996).

25 Francisco de Toledo, virrey de Perú entre los años1561-1581, autor de las reformas explicadas en la nota 23.

26 El abandono de las reducciones posibilitaba a los huidos el reclamo del status de forasteros, pudiendo así pagar un tributo menor con respecto de los indígenas que seguían adscriptos a sus ayllus y quedando exceptuados de la mita toledana. En general, el proceso es visto como negativo porque contribuyó a desgastar la base comunitaria de los ayllus (Andrien, 1996).

27 El diagnóstico de la situación virreinal sobre el que se basaron las reformas toledanas fue posibilitado por una Visita General realizada entre los años 1570 y 1575 (Andrien, 1996). 
fueron empadronados a los efectos de que tributasen [los que pasaron a llamarse] criollos" (Moreno, [1802] 1943, p. 18). Mientras que los indios forasteros - que continuaron arribando a las ciudades y no tenían domicilio fijo- siguieron llamándose "Yanaconas de la Rl Corona". Sobre los Yanaconas de las Chacras, empezó pronto una disputa por parte de los hacendados para retenerlos en sus dominios, en virtud del beneficio que les reportaba su fuerza de trabajo, "reputándolos obligados a vivir en las Haciendas, que primero habían elegido, sin libertad ni facultad para poder mudar de habitación".

Moreno narra en detalle la situación de estos yanaconas a fines del siglo XVI basándose en las referencias del "Sor Solarzano" (Moreno, [1802] 1943, p. 19) 28. Otros hacendados negaban incluso el hecho de que los yanaconas hubiesen llegado a trabajar libremente, sino que alegaban que estos habían sido transferidos por las autoridades en virtud de ser indios forasteros, para que cumpliesen con sus obligaciones tributarias. De este modo, ciertos españoles argumentaron que, tanto estos indios como su descendencia, habían quedado adscriptos a sus posesiones y que por esto les fue impuesto en nombre de Yanaconas, "qe en el lenguage de estas Provincias significa Indios de servicio” (Moreno [1802] 1943: 20).

Moreno argumenta otra vez en contra de estas prácticas abusivas, entendiendo que tanto la libertad como los privilegios de los indios estaban amparados por la ley. El problema seguía siendo la contradicción entre lo asentado en la jurisprudencia y la utilidad real de los yanaconas de chacras, en un momento de una brusca caída poblacional, como lo fue el contexto de fines del siglo XVII (Stern, 1982, p. 85), y la continuidad obvia de este beneficio en los momentos en que la Disertación se redactó (1802).

Posteriormente, la Disertación se introduce en el trabajo de los mitayos. Recordemos que la mita es una institución propiamente andina que sufrió transformaciones a lo largo de su desarrollo histórico. En la época preincaica consistía en prestaciones rotativas destinadas a trabajos comunitarios o en beneficio del curaca. Tiempo después, durante el incario, siguió manteniendo su forma anterior, pero se agregaron prestaciones temporarias para el Estado (agricultura, obras públicas, servicio militar). Luego, en el periodo colonial temprano, la mita estaba constituida, por un lado, por contingentes de indios de encomienda temporalmente afectados a trabajos públicos por pedido de los Cabildos y, por el otro, por trabajos colectivos para cumplir con el tributo a la Corona. Finalmente, la mita toledana mantuvo

\footnotetext{
28 Se trata de Juan de Solórzano Pereyra, quien en su obra Politica indiana defendióla igualdad entre criollos, españoles e indígenas (Tabarrozzi, 2012).
} 
el segundo aspecto de la mita colonial temprana, pero agregó la movilización de grandes contingentes de indios para cumplir con trabajos en minas, obrajes y haciendas en forma asalariada, temporal y rotativa (Quarleri, 2011). Es claro que, en la Disertación, Moreno se refiere a la mita minera producto de las reformas toledanas (ff. siglo XVI).

Luego de una introducción en la que se aborda la importancia de la industria minera en la historia humana, el autor señala que las disputas entre las diversas potencias por los territorios colonizados por España no se debieron a "[nuestra] situación ni civilización [...] sino [a] las muchas minas, qe se descubrieron en ella" (Moreno, [1802] 1943, p 24). El autor relata que el beneficio principal que obtenía la Corona de sus reinos americanos derivaba de la extracción de la plata y que "La publica y comun utilidad [...] y la natural y notoria resistencia de los Indios a todo trabajo [...] precisaron a nuestros Monarcas á determinar un servicio, qe a primera vista parece enteramte repugnante con la privilegiada libertad de los habitantes de estas provincias" (Moreno, [1802] 1943, pp. 25-26).

En esta parte del documento, Moreno se encuentra forzado a aceptar que la coacción a que fueron sometidos los indígenas fue obra de la Corona, no de ciudadanos particulares. Y lo hace apelando a la doctrina del bien común: "Jamás una Republica sera bien ordenada, mientras sus miembros no hagan comunes todos aquellos trabajos, que son necesarios para la conservacion y subsistencia del estado, y si ellos se hacen sordos á tan indispensable deber, incumbe a las Supremas potestades, que los goviernan, compelerlos al puntual desempeño de aquella sagrada obligación" (Moreno, [1802] 1943, p. 26).

Recordemos que la mita minera de Toledo comenzó en 1571, en un contexto de caída abrupta de la producción. Inicialmente, 16 corregimientos estaban obligados a enviar un séptimo de la población tributaria de cada repartimiento, hasta alcanzar un total de 14.000 mitayos anuales (cifra que se alcanzó en el repartimiento de 1578), en tandas renovadas cada siete años (Bakewell, 1989).

En adelante, con el afán de morigerar el peso de esta coacción sobre las libertades de los indígenas, Moreno recuerda las circunstancias excepcionales en que Toledo reestructuró el sistema de extracción de mineral "que urgían por aquel tiempo, y qe cesando estas, no debía proseguirse en aquella tolerada introducción" (Moreno, [1802] 1943, p. 26). De todos modos, como la "situación urgente" siguió prolongándose a través de los años, el autor se propone demostrar que a los monarcas les causaba aversión la situación de los indios mitayos, intentando que sean suplidos en sus tareas por esclavos negros o indios asalariados (Moreno, [1802] 1943, p. 27). 
Como prueba de lo anterior, Moreno narra que Felipe III (1578-1621) ordenó en 1601 al virrey de Perú, "Sor Dn Luis de Velasco", ${ }^{29}$ que procediese a una visita general a la ciudad de Potosí (actual Bolivia) con el objeto de informarse sobre el número y procedencia de los indígenas afectados a la mita, a fines de iniciar una política tendiente a fiscalizar que las condiciones de trabajo de los mitayos sean las adecuadas (tiempo de estadía, salubridad, pago de salarios) y a tratar en adelante de priorizar el trabajo en las minas de los indígenas de regiones vecinas (Moreno, [1802] 1943, pp. 26 y 28).

Posteriormente, el autor refiere una disputa alrededor de la mita minera contemporánea a la llegada de Moreno al Alto Perú (Moreno, [1802] 1943, p. 29). Dejaré este tema para el apartado dedicado al análisis del contexto de producción de la fuente. Acto seguido, el autor describe el trabajo en las minas, y vuelve a concluir que este, como cualquier servidumbre, es incompatible con la libertad de los indígenas (Moreno, [1802] 1943, p. 29):

Se ven continuamte sacarse violentamte á estos infelices de sus hogares y Patrias, para venir a ser victimas de una disimulada inmolacion. Puestos contra las LL. en Temples [por climas] enteramte diversos de aquellos en qe han nacido, se ven precisados a entrar pr conductos estrechos y subterraneos cargando sobre sus hombros los alimentos herramientas necesarias para su labor, á estar enterrados por muchos [días] ásacar después los metales qe han excavado sobre sus mismas Espaldas [...] padecimientos qe unidos á el mal trato [...] ocasionan, qe de las quatro partes de Indios, qe salen para la mita, rara vez regresen á sus Patrias las tres enteras (Moreno, [1802] 1943, p. 31).

Moreno aduce que la mita minera fue una creación más entre otras, como la de obrajes y haciendas, y que las mitas de estos otros ramos se hallaban a la fecha revocadas o derogadas, y que solo...

los Mineros de Potosí se han de mantener tenaces, en querer sostener á sangre y fuego una Mita la más irregular y repugnante á los indisputables dros. de los indios. Ignoran acaso, qe este fué un auxilio subsidiario, que se les concedio solamte mientras se proveian de operarios voluntarios para el efecto? [...] Diran acaso que no bastan las producciones de aquel Cerro para los jornales? Y que necesidad hay de trabajar unas Minas, que no sufragan á los indis-

29 Luis de Velasco y Castilla, marqués de Salinas, virrey de Nueva España (1590-1595, 1607-1611) y de Perú (15961604). 
pensables gastos de su beneficio? [...] Lo cierto es qe si se han suprimido las Encomiendas, ${ }^{30}$ por considerarse poco conformes á la libertad y privilegio, de los Indios se puede esperar lo mismo con el servicio de la Mita" (Moreno, [1802] 1943, p. 33).

La Disertación termina con un presagio de "cambio de época" en referencia a la mita, ya que "á lo menos varias veces se ha pensado ya en la Corte su supresión" (Moreno, [1802] 1943, p. 33).

\section{Conclusiones}

El análisis preliminar del texto de la Disertación permite proponer que esta constituye una defensa de los pueblos originarios basada en la idea del "buen salvaje" de Rousseau, autor de la predilección de Moreno. Según el mismo, los indígenas con que Cristóbal Colón se topó en los inicios de la conquista no solo eran seres racionales, sino que tenían una forma de gobierno y una cultura relevantes. Sin embargo, el proceso histórico posterior supuso una contradicción entre la jurisprudencia real - que amparaba a los indígenas - y las prácticas de los conquistadores, a través de las cuales estos fueron transformados en mano de obra esclava. Es así como "Moreno, que bajo la obediencia al rey cuestionaba a los poderes locales, y en tal sentido se posicionaba en favor de los indios y en contra de sus explotadores, indicaba que, así como los monarcas emitían leyes protectoras de la libertad de los indios, la realidad construida por los gobiernos locales venía a contradecirlas una y otra vez a lo largo de los siglos" (Tabarrozzi, 2012, p. 18). A sí visto, el objetivo claramente político de la Disertación es "cumplir [...] con el interes qe uno debe mirar los derechos de aquellos hombres, cuyas regiones habita" (Moreno, [1802] 1943, p. 7), con lo que Moreno propone una comunidad de intereses entre criollos e indígenas funcional a los escarceos revolucionarios.

A este respecto, existe una clara tensión entre el "nosotros" al que alude Moreno (los "americanos" criollos e indígenas) y la estructura real de la sociedad de castas colonial, con una neta separación entre "blancos" (criollos, españoles) e indígenas. La condición estructural de tal separación, versus el ideal ecuménico planteado por Moreno, sería evidente cuando se instauró el nuevo orden republicano, y los

\footnotetext{
30 La encomienda empezó a declinar luego de la derrota de Gonzalo Pizarro en 1548 y, conforme el poder real empezó a ejercer un más efectivo dominio, fue abolida durante el reinado de Felipe V (1700-1724, 1724-1746), primer rey español de la Casa de Borbón (Elliot, 1990).
} 
pueblos de indios se transformaron en comunidades indígenas, sin que el pasaje de siervo a ciudadano comportara una mejora sustancial en los pueblos originarios. ${ }^{31}$

Tanto la introducción como la parte primera de la Disertación sirven como base argumentativa a la posición que el autor adoptará sobre el problema de la mita minera, y que sigue la defendida por Victorián Villaba. El trabajo forzado en las minas era un tema candente en aquella región y aquella época, cuando todavía no se habían apagado los ecos de la rebelión de 1780. Entendiendo que había llegado la hora de reconocer que todos los hombres nacían iguales, la Disertación argumentaba en favor del derecho de los indígenas a elegir libremente su trabajo vetando el uso de la coacción para los servicios personales. Como vimos, en esta doctrina tuvieron un rol esencial las universidades, como la de Charcas, en la se formó gran parte de la intelectualidad de las Provincias Unidas del Río de la Plata. La ampliación de esta investigación deberá abordar en el futuro las características de esta "red" particular a la que se sumó Moreno, formada por intelectuales religiosos y laicos, lo que nos permitirá tener un entendimiento más acabado de los vínculos interpersonales de los diferentes actores.

Los nuevos tiempos en los que la Disertación se inscribe son particularmente visibles en el lenguaje político "propio de los autores europeos más frecuentados, con un repertorio de categorías que conllevaban una especial carga significante dirigida a cambiar la visión interpretativa y la propia realidad social". Eran de uso común los conceptos de "soberanía, voluntad general, nación, división de poderes, representación, derechos naturales" y colisionaban "vocablos opuestos como 'libertad civil' o 'nativa libertad' versus esclavitud, y castas versus hombres libres o hermanos" (Seghesso, 2010: 32). Coincidentemente, es notorio el uso recurrente que hace Moreno de la palabra libertad (y de variantes como privilegiada libertad, nativa libertad, perfecta libertad, libertad legítima, decantada libertad, natural libertad, primitiva libertad, privilegiada libertad, libertad como derecho, etcétera) y de significantes asociados como razón, república, derechos. Lo que resalta aún más si tomamos en cuenta que el autor escribe como vasallo, respetando la debida sumisión al rey.

Siguiendo a De Gori (2016), podemos proponer que el texto de Moreno se inscribe en una producción mayor que dio cuenta de las luchas políticas producidas

31 Por otro lado, cabe preguntarse si en la Disertación Moreno realmente habla de la esclavitud indígena o si solo equipara el sistema de trabajos forzados con la esclavitud. Pesquisas futuras deberían poder aclarar si el autor considera el trabajo forzado trabajo esclavo, si aduce que este simula trabajo esclavo, o si solo hace referencia a la contradicción entre las leyes de la Corona en favor de los pueblos originarios y su no aplicación. Debo esta inquietud a un planteamiento realizado por uno de los evaluadores de este texto. 
en el periodo que abarcó desde la instauración de las reformas borbónicas hasta la Asamblea de 1813 (Buenos Aires). Estas contiendas involucraron la reactualización de imaginarios políticos pertenecientes al universo de la monarquía hispana para fundamentar los nuevos cursos de acción y las diferentes respuestas ante el contexto sociopolítico de crisis. Por entonces, los "hombres de saber", a través de sus "textos de combate", no solo dieron cuenta de su posición en las diversas polémicas, "sino que se tornaron indispensables para la disputa representacional e imaginaria. Ellos, intentando animar la discusión y la polémica, establecieron marcos interpretativos sobre conflictos y tensiones" (De Gori, 2016, p. 226).

Por lo anterior, es posible proponer que el estudio de la Disertación y otras fuentes similares puede ayudarnos a comprender la ideología de los sectores liberales de la época, ya que se enmarca en el campo de los debates universitarios y políticos alrededor de los problemas de las instituciones coloniales, lo cual se entronca, a su vez, con la historia intelectual de la élite revolucionaria suramericana que se educó en el Alto Perú y que mostraba sus críticas al sistema colonial desde antes de la invasión napoleónica a España. ${ }^{32}$

Desde esta perspectiva, la lectura de la Disertación posibilita adelantar líneas interpretativas alrededor de ciertos conflictos y cambios finiseculares. En vista a un futuro análisis más detallado, propongo abordar esta fuente de acuerdo con estos tentativos, múltiples e interrelacionados estratos de significación: 1) en tanto requisito académico cumplimentado por Mariano Moreno para la obtención de su título de abogado, formando parte de su historia de vida, en el sentido propuesto por Bertaux (1993, p. 3); 2) como herramienta jurídica, en tanto la fuente aborda en detalle la recopilación de las leyes indianas atinentes al estatuto de vasallo en relación con los indígenas; 3) en tanto continente de una determinada postura ideológica, 4) reveladora de un campo de poder en construcción, entretejido alrededor de los diversos personajes que aparecen, adscriptos a grupos en disputa, y 5) como expresión de a) una determinada situación socio-económica-política pronta a desembocar en profundos reacomodamientos y b) la problemática de la otredad en el marco de las relaciones dominantes-dominados en las nacientes repúblicas americanas.

Por todo lo anterior, considero que la Disertación constituye un documento muy rico para ser examinado mediante una perspectiva que combine, de un lado, el análisis de la estructura social con el de los acontecimientos y, del otro, los enfoques en escalas micro y macro, a través de un análisis textual que "privilegie el análisis de 
procesos, dinámicas y situaciones cotidianas y detalles menores" (Rodríguez, 2012, p. 6). Considero que un planteamiento de este tipo constituye una contribución al trabajo investigativo interdisciplinario sobre relaciones sociales históricamente determinadas, aportando un punto de vista particular sobre las múltiples temáticas que en este documento conviven.

\section{BiBLIOGRAFÍA}

Andrien, K. (1996). Españoles, andinos y el estado colonial temprano en el Perú. Memoria Americana (4): 11-32.

Arrom, J. (1992). Las primeras imágenes opuestas y el debate sobre la dignidad del indio. En M. Gutiérrez Estévez y M. León Portilla (comps.). De palabra y obra en el Nuevo Mundo (pp. 63-85). Distrito Federal, México: Siglo XXI.

Bakew ell, P. (1989). Mineros de la Montaña Roja. Madrid, España: Alianza.

Bertaux, D. (1999). El enfoque biográfico. Su validez metodológica, sus potencialidades. Proposiciones, 29(marzo): 1-22.

Elliot, J. (1990). La conquista española y las colonias de América. En L. Bethell (dir.). Historia de América Latina (tomo 1). Barcelona, España: Cambridge University Press, Editorial Crítica.

Flores Galindo, A. (1993). Buscando un inca. Identidady utopia en los Andes. Distrito Federal, México: Grijalbo.

DE GorI, E. (2012). La revolución patriota. Travesías de los imaginarios y de los lenguajes politicos en elpensamiento de Mariano Moreno. Buenos Aires, Argentina: EUDEBA.

DE Gori, E. (2013). Narraciones compartidas: Imaginarios políticos entre Charcas y Buenos Aires (de las reformas borbónicas al proceso juntista). Procesos. Revista Ecuatoriana de Historia, 37(enero-junio): 57-79. Recuperado de http://revistaprocesos. ec/ojs/index.php/ojs/article/view/18/38.

De Gori, E. (2016). Hombres de saber y de acción en tiempos convulsionados: Imaginarios y lenguajes sobre el orden político en Charcas (Desde las Reformas Borbónicas hasta la Asamblea del Año XIII). Anuario de Estudios Americanos, 73(1): 199-229. DOI: http://dx.doi.org/10.3989/aeamer.2016.1.07.

Hanke, L. (1982). La humanidad es una. Distrito Federal, México: Fondo de Cultura Económica.

Levene, R. (1921). Ensayo histórico sobre la Revolución de Mayo y Mariano Moreno (Contribución al estudio de aspectos político, jurídico y económico de la revolución 
de 1810). Buenos Aires, Argentina: Facultad de Derecho y Ciencias Sociales de la Universidad de Buenos Aires.

Levene, R. (comp.) (1943) Mariano Moreno. Escritos. Buenos Aires, Argentina: Estrada. Levene, R. (1948). Las ideas politicas y sociales de Mariano Moreno. Buenos Aires, Argentina: Emecé.

LoR ANDI, A. (2002). Ni ley, ni rey ni hombre virtuoso. Guerra y sociedad en el Virreinato del Perú. Siglos XV y XVII. Barcelona, España: Gedisa.

LorAndi, A., y Wilde, G. (2000). Desafío a la isocronía del péndulo. Acerca de la teoría y la práctica de la antropología histórica. Memoria Americana (9): 37-78.

Manzanelli, M. (2014). Reseña. La república patriota. Travesías de los imaginarios y de los lenguajes políticos en el pensamiento de Mariano Moreno. Esteban De Gori. Buenos Aires, Eudeba, 2012. Andes, 25(2): 3 p. Recuperado de http://www. scielo.org.ar/pdf/andes/v25n2/v25n2a08.pdf.

Moreno, M. ([1802] 1911). Disertación Jurídica sobre el servicio personal de los indios en general y en particular de Yanaconas y Mitaxios. Revista de Derecho, Historia $y$ Letras, XXXVIII: 377-391 y 582-594.

Moreno, M. ([1802] 1943). Disertación jurídica. Sobre el servicio personal de los Indios en general, y sobre el particular de Yanaconas y Mitarios. Que se ha de leer en la R.l Academia de práctica de Jurisprudencia de esta Ciudad, por el Académico que suscribe, el día de Agosto de 1802. En R. Levene R. (comp.) Mariano Moreno. Escritos (pp. 5-34). Buenos Aires, Argentina: Estrada.

QUARLERI, L. (2011). Material complementario de la materia Sistemas Socioculturales de América II. Buenos Aires, Argentina: Facultad de Filosofía y Letras de la Universidad de Buenos Aires.

Seghesso, M. (2010). La Revolución de Mayo y los indígenas. Vivencias y políticas vindicatorias. Revista Historia del Derecho, 39(enero-junio): 1-34.

Stern, S. (1982). Los pueblos indigenas del Perú y el desafío de la Conquista Española. Madrid, España: Alianza.

Tabarrozzi, S. (2012). Mariano Moreno: La defensa de los indios. Actas de las VII Jornadas de Sociología de la Universidad Nacional de La Plata: "Argentina en el escenario latinoamericano actual: Debates desde las ciencias sociales" (pp. 1-21). Recuperado de http://jornadassociologia.fahce.ulp.edu.ar.

O'phelan, S. (1988). Un siglo de rebeliones anticoloniales. Perú y Bolivia. 1700-1783. Cusco, Perú: Centro Bartolomé de las Casas.

Ramos, A. (2016). El desarrollo de la etnohistoria andina como campo interdisciplinar: Interacciones entre historia, arqueologia y antropologia (Perú, Bolivia y Argentina, 
1970-2005) (Tesis de doctorado). Universidad de Buenos Aires, Buenos Aires, Argentina.

Real Academia Española (2014). Diccionario de la lengua española. Edición del tricentenario. Recuperado de http://dle.rae.es/.

RodríGUez, L. (2012). Un pueblo de indios a fines de la colonia. Transcripción, análisis y reflexiones metodológicas a partir de un expediente criminal inédito. Corpus, Archivos Virtuales de la Alteridad Americana, 2(1). Recuperado de http://ppct. caicyt.gov.ar/index.php/corpus/article/view/634/0.

Sahlins, M. (1985). Islands of History. Chicago, Estados Unidos: University of Chicago Press.

Serulnikov, S. (2010). Revolución en los Andes. La era de Tupac Amaru. Buenos Aires, Argentina: Sudamericana.

Walker, C. (1999). De Tupac Amaru a Gamarra. Cusco y la formación del Perú Republicano. 1780-1840. Cusco, Perú: Centro de Estudios Rurales Andinos Bartolomé de las Casas.

Wieczorek, T. (2012). Reseña bibliográfica. La república patriota. Travesías de los imaginarios y de los lenguajes políticos en el pensamiento de Mariano Moreno. Esteban De Gori. Buenos Aires, Eudeba, 2012. Anacronismo e Irrupción. Revista de Teoria y Filosofía Politica Clásica y Moderna, 3(4): 240-244. Recuperado de http://www.saavedrafajardo.org/Archivos/ai030411.pdf. 